\title{
Crescimento inicial de Piptadenia stipulacea (Benth.) Ducke (Mimosaceae) e Anadenanthera colubrina (Vell.) Brenan var. cebil (Griseb.) Altshul (Mimosaceae) sob diferentes níveis de sombreamento
}

Wanessa Nepomuceno Ferreira ${ }^{1,4}$, Roberta Boscaini Zandavalli², Antônio Marcos Esmeraldo Bezerra ${ }^{3}$ e Sebastião Medeiros Filho ${ }^{3}$

Recebido em 21/07/2011. Aceito em 27/02/2012

\section{RESUMO}

(Crescimento inicial de Piptadenia stipulacea (Benth.) Ducke e Anadenanthera colubrina (Vell.) Brenan var. cebil (Griseb.) Altshul (Fabaceae) sob diferentes níveis de sombreamento). Este trabalho teve como objetivo verificar como as características morfofisiológicas diferem entre duas espécies da Caatinga com diferentes necessidades de luz para o crescimento inicial, apresentando a hipótese de que P. stipulacea caracteriza-se como espécie heliófila e A. colubrina como umbrófila, nas primeiras fases de vida. Conduziu-se um experimento em blocos ao acaso, no qual plântulas de ambas as espécies foram submetidas aos tratamentos de pleno sol, 50\%, 70\% e 90\% de sombra durante seis meses. Foram avaliados aspectos morfológicos (altura, diâmetro, número de folhas e alocação de biomassa) e fisiológicos (teores de clorofila $a, b$ e total, e razão clorofila $a / b$ ). Os resultados mostraram que as espécies apresentam diferentes exigências de luz durante o crescimento inicial. Plântulas de P. stipulacea apresentaram maior taxa de crescimento relativo e maior diâmetro a pleno sol, menor razão raiz/parte aérea e menor conteúdo de clorofila total quando comparadas às plântulas de A. colubrina. Os melhores resultados de P. stipulacea a pleno sol e A. colubrina em níveis intermediários de sombra corroboraram com a hipótese deste trabalho e são consistentes com a área de ocorrência de cada espécie.

Palavras-chave: biomassa, clorofila, heliófila, umbrófila

\begin{abstract}
(Early growth of Piptadenia stipulacea (Benth.) Ducke and Anadenanthera colubrina (Vell.) Brenan var. cebil (Griseb.) Altshul (Fabaceae) exposed to different levels of shade). This study aimed to verify how morpho-physiological characteristics differ between species of the Caatinga with different light requirements for initial growth, and had the hypothesis that $P$. stipulacea is light-demanding and A. colubrina is shade-tolerant in the early stages of life. We conducted a randomized block experiment in which seedlings of both species were subjected to treatments of full sun, $50 \%, 70 \%$ and $90 \%$ shade for six months. We evaluated morphological (height, diameter, number of leaves and biomass allocation) and physiological ( $a, b$ and total chlorophyll content, and ratio of chlorophyll $a / b$ ) features. The results showed that these species have different light requirements during early growth. Seedlings of $P$. stipulacea showed a higher relative growth rate and larger diameter when growing in full sun, and a lower root/shoot ratio and lower total chlorophyll content when compared to seedlings of A. colubrina. The best results were for $P$. stipulacea in full sun and A. colubrina at intermediate levels of shade, which corroborate the hypothesis of this work and are consistent with where each species grows.
\end{abstract}

Key words: biomass, chlorophyll, light-demanding, shade-tolerant

\footnotetext{
1 Universidade Federal do Ceará, Programa de Pós-Graduação em Ecologia e Recursos Naturais, Fortaleza, CE, Brasil

2 Universidade Federal do Ceará, Departamento de Biologia, Fortaleza, CE, Brasil

3 Universidade Federal do Ceará, Departamento de Fitotecnia, Fortaleza, CE, Brasil

4 Autora para correspondência: wanessanepomuceno@hotmail.com
} 


\section{Introdução}

Florestas tropicais possuem um mosaico de diferentes ambientes de luz, que variam de sub-bosques sombreados a clareiras de vários tamanhos, levando a uma significativa heterogeneidade de adaptações a esses diferentes gradientes de luz (Valladares et al. 2000). Assim, em função da luz, as espécies vegetais podem ser agrupadas em dois grandes grupos: espécies pioneiras (heliófilas), que requerem radiação solar direta para a germinação e o crescimento satisfatório de suas plântulas, e espécies clímax (umbrófilas), que são tolerantes ao sombreamento inicial, podendo germinar, sobreviver e desenvolver-se sob dossel fechado, com pouca luz. Este último grupo é subdividido em espécies clímax exigentes de luz e clímax tolerantes à sombra (Swaine \& Whitmore 1988).

As espécies arbóreas variam grandemente na sua capacidade de responder a alterações na disponibilidade de luz (Thompson et al. 1992). Pesquisas relacionadas aos efeitos do sombreamento sobre o crescimento dos vegetais demonstram que, comparadas às plantas de sol, as plantas de sombra apresentam entre outras características, maior área foliar, menor matéria seca, menor relação de clorofila $a / b$, menor taxa de fotossíntese, menor intensidade de respiração e transpiração, e menor taxa de crescimento relativo (Lüttge, 1997; Larcher, 2006).

Atualmente, registram-se muitos trabalhos sobre a influência do sombreamento no crescimento inicial de espécies de florestas úmidas, ou seja, ambientes com evidentes gradientes de sombra (Uchida \& Campos 2000; Nakazono et al. 2001; Campos \& Uchida 2002; Duz et al. 2004; Silva et al. 2007; Souza et al. 2009). Entretanto, nota-se um escasso interesse científico no conhecimento da influência do sombreamento sobre as espécies de fitofisionomias predominantemente abertas e alta incidência solar, como a vegetação da Caatinga.

É importante ressaltar que, na época chuvosa, a Caatinga apresenta cobertura das copas, maior quantidade de estrato herbáceo e serrapilheira, e estas condições fazem com que na fase de germinação, algumas espécies se comportem como tolerantes à sombra (Barbosa 2003). Considerando que, no período chuvoso, a Caatinga apresenta gradientes de sombra, ainda mais evidentes comparando-se áreas perturbadas e conservadas, pressupõe-se que as espécies presentes nestes ambientes contrastantes apresentem diferentes requerimentos de luz para germinação e crescimento inicial.

Ao analisar trabalhos fitossociológicos realizados em áreas de Caatinga, percebe-se que algumas espécies, tais como Croton sonderianus Mull. Arg., Caesalpinia pyramidalis Tul., Aspidosperma pyrifolium Mart. e Piptadenia stipulacea (Benth.) Ducke predominam em áreas perturbadas, enquanto outras espécies como Myracrodruon urundeuva Allemao, Amburana cearensis (Allemao) A.C.Sm. e Anadenanthera colubrina (Vell.) Brenan predominam em áreas conservadas (Pereira et al. 2001; Andrade et al. 2005;
Queiroz et al. 2006; Barbosa et al. 2007). Com base nestes pressupostos, avaliou-se o crescimento inicial de $P$. stipulacea e A. colubrina, com a hipótese de que estas espécies possuem diferentes requerimentos de luz para o crescimento inicial, sendo que, nas primeiras fases de vida, $P$. stipulacea caracteriza-se como espécie heliófila e A. colubrina como umbrófila.

Piptadenia stipulacea (Benth.) Ducke é uma espécie da família Fabaceae, conhecida popularmente como jurema branca, que ocorre na caatinga, do Piauí até a Bahia (Braga 1976). A árvore é pequena, com cerca de 2-4 m de altura, casca castanho-claro, fortemente armada por acúleos vigorosos. Seu fruto é uma vagem de cor castanho-pálido, com 8-12 cm de comprimento, com superfície ondulada nas áreas onde ficam as sementes. Contém de 2 a 12 sementes ovais pequenas, por vagem, de cor marrom. Segundo Pereira et al. (2001), o comportamento de P. stipulacea reflete nitidamente os efeitos das perturbações a que uma vegetação foi submetida, mostrando-se bastante tolerante a elevados níveis de perturbação.

Anadenanthera colubrina (Vell.) Brenan var. cebil (Griseb.) Altshul é uma espécie da família Fabaceae, comum em todo Nordeste brasileiro, conhecida popularmente como angico. Na caatinga, apresenta altura entre 3 a 15 $\mathrm{m}$, enquanto em outros ecossistemas atinge de 20 a 30 $\mathrm{m}$, com diâmetro de até mais de um metro (Maia 2004). Possui caule pouco tortuoso e mediano, de casca grossa, muito rugosa, fendida e avermelhada. $\mathrm{O}$ fruto é uma vagem achatada, grande, de até $32 \mathrm{~cm}$ de comprimento (Braga 1976). Esta espécie possui grande demanda no mercado, sendo utilizada como ornamental, fornecedora de tanino e mel, forrageira, energética, resinífera, madeireira e, inclusive, medicinal. Esse uso intenso, até por indústrias, coloca em risco a existência dessa e de outras espécies, aliado à ausência de cultivos ou de métodos de propagação, ao desconhecimento da real distribuição das populações nativas e à ausência de estudos que avaliem o impacto do extrativismo na estrutura e biologia dessas populações (Albuquerque \& Andrade 2002).

Este trabalho teve como objetivo verificar como as características morfofisiológicas diferem entre duas espécies da Caatinga com diferentes necessidades de luz para o crescimento inicial, visto que conhecer o comportamento das plântulas de espécies nativas, quanto aos fatores ecofisiológicos, é essencial para o entendimento do processo sucessional e, conseqüentemente, para a restauração da vegetação em ambientes degradados.

\section{Material e métodos}

Em abril de 2010, amostras de ramos com flores e frutos, de ambas as espécies, foram coletadas de plantas matrizes localizadas em área de caatinga situada na fazenda "Não Me Deixes", Reserva Particular do Patrimônio Natural-RPPN (449’34"S, 3858'9"W e 210 m de altitude), em Quixadá, 
Ceará. Após coleta, o material botânico foi encaminhado para o Herbário Prisco Bezerra-EAC da Universidade Federal do Ceará-UFC, onde foi herborizado. Em seguida, as espécies foram identificadas como Piptadenia stipulacea (Benth.) Ducke e Anadenanthera colubrina (Vell.) Brenan var. cebil (Griseb.) Altshul, sendo as exsicatas depositadas, no EAC, sob números 47.038 e 46.898 , respectivamente. Os frutos utilizados no experimento foram coletados, manualmente, de pelo menos sete indivíduos adultos de cada espécie, visando obter uma variabilidade genética na amostra. As vagens foram acondicionadas em sacos devidamente etiquetados e conduzidas ao Laboratório de Análise de Sementes-LAS, pertencente ao Centro de Ciências Agrárias da UFC, onde foram realizadas a retirada das sementes dos frutos e a limpeza e separação das sementes mal-formadas e/ou predadas por insetos.

Em maio de 2010, sementes de P. stipulacea foram submetidas a um tratamento de superação de dormência (ácido sulfúrico por 10 minutos) no LAS. Em seguida, as sementes de ambas as espécies foram conduzidas para o Núcleo de Ensino e Pesquisa em Agricultura Urbana-NE-

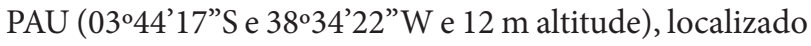
no Campus do Pici da UFC, em Fortaleza-Ceará. No NEPAU foi realizada a semeadura indireta das sementes de $P$. stipulacea e A. colubrina, em bandejas plásticas contendo mistura de solo (extraído da área de caatinga em Quixadá) e húmus na proporção volumétrica de 3:1. Esta etapa do experimento foi conduzida em casa de vegetação, onde foram feitas irrigações diárias, por meio de micro-aspersão e nebulização, sempre na mesma quantidade em todas as bandejas, para manter a umidade adequada à emergência das plântulas. Após atingirem $5 \mathrm{~cm}$ de altura (15 dias após semeadura), as plântulas foram transplantadas para sacos de polietileno preto-opaco de $15 \times 25 \mathrm{~cm}$ com perfurações laterais e substrato contendo solo de Quixadá e húmus na proporção volumétrica de 2:1. A primeira coleta de dados foi realizada um mês após a semeadura, e se caracterizou como mensurações da altura, diâmetro do coleto e número de folhas de cada plântula, em cada espécie.

Após a primeira coleta, as plântulas foram submetidas aos tratamentos com diferentes graus de irradiância. Os sacos com as plântulas foram colocados sobre uma base de $1 \mathrm{~m}^{2}$ feita com tijolos de cerâmica, elevada a $15 \mathrm{~cm}$ do nível do solo e sobre cada base foi colocada uma armação de $2 \mathrm{~m}$ de altura, confeccionada com ferro e madeira, e coberta com tela sombrite, permitindo a passagem de $50 \%, 30 \%$ e $10 \%$ da luz solar incidente, conforme especificação do fabricante das telas. Os quatro tratamentos realizados consistiram em: tratamento 1 - pleno sol ( $0 \%$ de sombreamento); tratamento $2-50 \%$ de sombreamento ( $50 \%$ em relação ao pleno sol); tratamento $3-70 \%$ de sombreamento (30\% em relação ao pleno sol) e tratamento $4-90 \%$ de sombreamento ( $10 \% \mathrm{em}$ relação ao pleno sol).

Após um mês em que as plântulas foram submetidas às condições de tratamento citadas, procederam-se mais cinco avaliações mensais para mensuração das variáveis citadas anteriormente, sendo os fatores dispostos num arranjo de parcelas subdivididas no tempo, seguindo um delineamento em blocos ao acaso com quatro repetições (11 mudas por repetição). As variáveis respostas foram mensuradas no programa Statistica 7.0 (STATSOFT 2004), utilizando uma análise de variância para medidas repetidas.

Decorridos seis meses após a semeadura, foram retiradas três plantas de cada unidade experimental para avaliação da matéria seca, totalizando, assim, para cada tratamento de sombreamento, 12 mudas de cada espécie. Subseqüentemente, como recomendado por Böhm (1979), o material vegetal das mudas foi dividido em raiz, caule e folhas, em seguida, foi colocado em estufa a $70^{\circ} \mathrm{C}$ até atingir peso constante, e pesado em balança de precisão de $0,01 \mathrm{~g}$. Foram avaliadas as massas secas da raiz (MSR), da parte aérea (MSPA), total (MST) e relação raiz/parte aérea (MSR/ MSPA). Calculou-se, também, a taxa de crescimento relativo da parte aérea (TCRPA).

Para a determinação do teor de clorofila, aos seis meses após semeadura, foi retirada a terceira folha do ápice para base, que se encontrasse totalmente expandida, de três plantas de cada parcela e por espécie, totalizando 12 plantas para cada nível de sombreamento. O material vegetal foi coletado no período da manhã e armazenado em sacos de papel alumínio etiquetados, acondicionados em caixa de isopor com gelo. Em seguida, as amostras foram transportadas para o LAS e, sob ambiente de luz verde, os pigmentos foram extraídos dos tecidos foliares por maceração em almofariz com acetona $80 \%(\mathrm{v} / \mathrm{v})$. As leituras de absorbância foram efetuadas em espectrofotômetro a 647nm (clorofila b) e 663 $\mathrm{nm}$ (clorofila a). A concentração de clorofila foi calculada segundo Whitham et al. (1971).

Os dados de massa seca, taxa de crescimento relativo e conteúdo de clorofilas foram submetidos à análise de variância no modelo de blocos ao acaso, e as médias foram comparadas pelo teste de Tukey, a 5\% de probabilidade, utilizando-se o programa SISVAR (Ferreira 2008).

\section{Resultados e discussão}

Observou-se, para ambas as espécies, que a altura aumentou com o aumento do sombreamento. Aos seis meses de idade, $P$. stipulacea apresentou maior média $(143,36 \mathrm{~cm})$ nas plantas submetidas a $90 \%$ de sombra, enquanto $A$. colubrina apresentou maior média $(50 \mathrm{~cm})$ a $70 \%$ de sombra (Fig. 1A e Fig. 1B). O alongamento do caule de mudas submetidas à baixa luminosidade é considerado uma resposta morfogênica típica (Smith \& Whitelam 1990). Notou-se que esta resposta foi mais evidente para $P$. stipulacea, visto que o sombreamento de plantas adaptadas às altas intensidades de radiação induz à alocação de maior quantidade de fotoassimilados para o crescimento em altura, possibilitando maior alongamento dos entrenós, fato que não ocorre nas plantas de sombra (Taiz \& Zeiger 2004). Sendo assim, trata-se de 

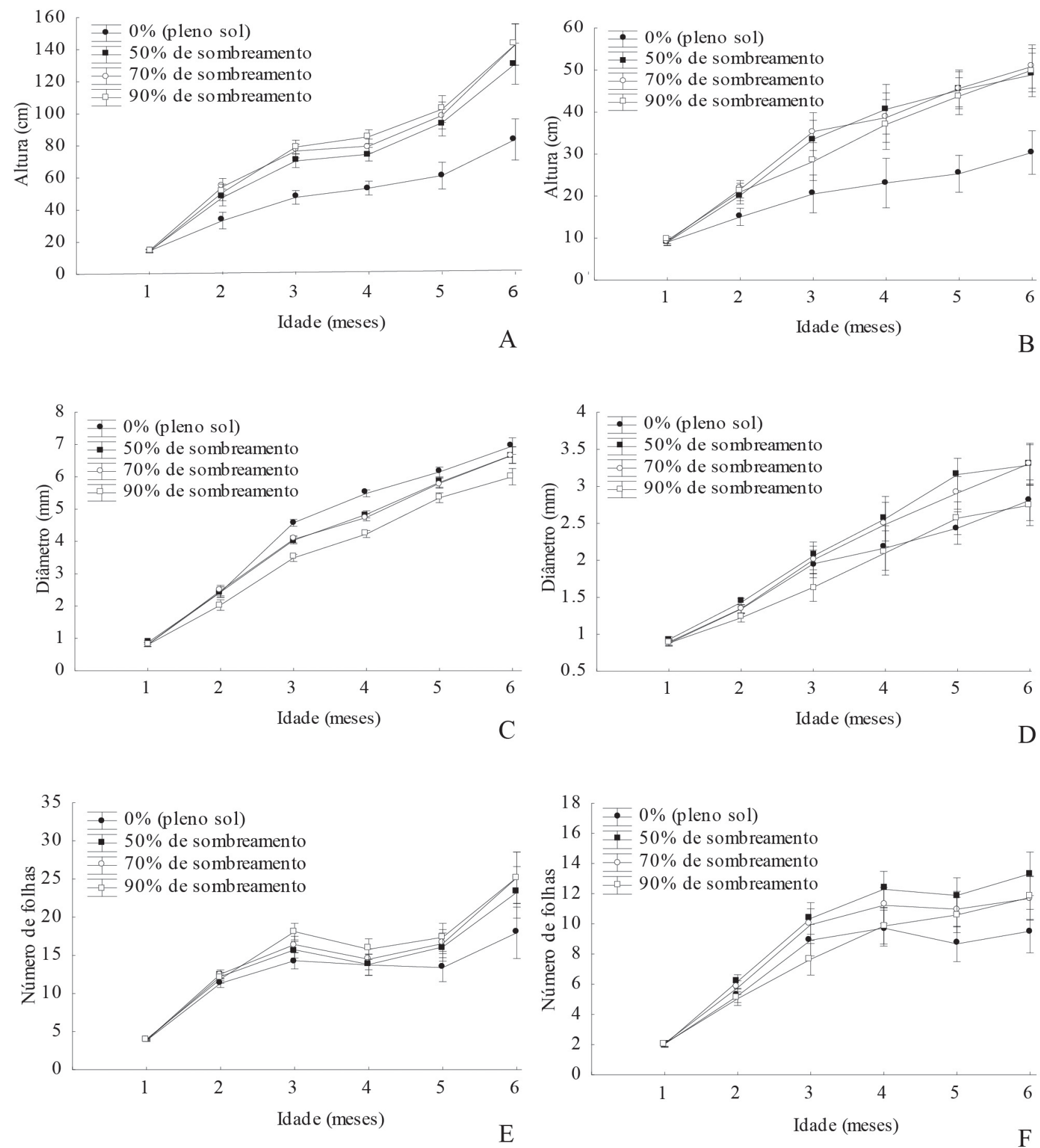

Figura 1. Altura (A), diâmetro (C) e número de folhas (E) das mudas de P. stipulacea; Altura (B), diâmetro (D) e número de folhas (F) das mudas de A. colubrina submetidas a diferentes níveis de sombreamento.

uma resposta associada às espécies arbóreas mais exigentes por luz que procuram superar a altura das plantas que as sombreiam (Poorter 1999).

Quanto ao diâmetro do colo verificou-se que, para plântulas de P. stipulacea, houve um aumento proporcional ao acréscimo da luminosidade. Aos seis meses de idade, as plantas expostas a pleno sol apresentaram maior média $(6,95$ $\mathrm{mm}$ ) e plantas sob $90 \%$ de sombra obtiveram a menor média
(6,0 mm) (Fig. 1C). Por outro lado, em A. colubrina, a maior média de diâmetro foi obtida no tratamento de $70 \%$ de sombra (3,3 mm), sem diferenças estatísticas dos tratamentos de $50 \%$ e pleno sol (Fig. 1D). Os resultados de diâmetro em $P$. stipulacea foram semelhantes aos encontrados por Felfili et al. (1999), quando mudas de Sclerolobium paniculatum Vog., espécie pioneira comum em floresta estacional, apresentaram maior diâmetro a pleno sol e 50\% de sombreamento. De acordo com 
estes autores, maiores valores de biomassa e do diâmetro do colo sob esses dois níveis de sombreamento podem ser características de espécies heliófilas em fases iniciais de sucessão, pois o tratamento a pleno sol pode representar uma condição de área de mata degradada e $50 \%$ de sombra pode representar uma condição de clareira em floresta natural. A maior média de diâmetro de A. colubrina a 70\% de sombreamento, sugere que esta espécie se desenvolve bem em ambientes sombreados. Segundo Reis et al. (1991), plantas com maior diâmetro apresentam melhores condições de sobrevivência por apresentarem maior capacidade de formação e crescimento de raízes novas.

Com relação ao número de folhas das plântulas de $P$. stipulacea, observou-se que a quantidade aumentou com o aumento do sombreamento. Sendo assim, a maior média foi obtida a $90 \%$ de sombreamento, que diferiu significativamente apenas do tratamento a pleno sol, com menor média (Fig. 1E). Para A. colubrina, foi registrada uma maior quantidade de folhas em plantas cultivadas em ambiente sob 50\% de sombreamento, sendo a média similar aos tratamentos de 70 e $90 \%$ de sombra, e diferente do tratamento a pleno sol, com menor média (Fig. 1F). A folha, principal órgão fotossintético, sofre alterações morfológicas e fisiológicas para aumentar a absorção de luz e maximizar o ganho total de carbono (Osunkoya et al. 1994). Com o acréscimo do nível de sombreamento, há uma tendência no aumento da área foliar (folhas mais finas e maiores), alocação de biomassa nas folhas e quantidade de folhas (Poorter 1999).

Devido ao caráter decíduo das espécies, observou-se em todos os tratamentos uma diminuição do número de folhas durante a estação seca. Neste mesmo período, também foi registrado o florescimento precoce de plantas no tratamento a pleno sol. A maior evaporação durante os meses de estiagem pode ter induzindo o florescimento precoce de alguns indivíduos como forma de "escape", ou seja, uma tentativa de completar o ciclo de vida antes de um déficit mais severo de água no solo e na planta. Distúrbios na região da raiz, como a deficiência hídrica ou uma deficiência de nutrientes e de oxigênio podem induzir uma "floração de emergência" (Larcher 2006). Essa floração prematura foi mais evidente em plantas de $P$. stipulacea, com o florescimento de seis indivíduos a pleno sol, enquanto que apenas um indivíduo de A. colubrina floresceu (Fig. 1E e 1F). Isto pode estar relacionado ao fato de que plantas que crescem sob forte radiação apresentam um metabolismo mais ativo, com maior produção e maior conteúdo energético de matéria seca, bem como uma floração e frutificação mais freqüente (Larcher 2006).

As duas espécies apresentaram menores taxas de crescimento relativo da parte aérea (TCRPA) a pleno sol, sendo que para todos os tratamentos, $P$. stipulacea apresentou maiores médias em relação a A. colubrina (Tab. 1 e Tab. 2). Esta resposta sugere que a espécie $P$. stipulacea possui uma menor tolerância à sombra, quando comparada a A. colubrina, visto que, espécies intolerantes a sombra geralmente apresentam rápido crescimento em altura em relação às espécies tolerantes (Whitmore 1990).
Quanto à acumulação da massa seca constatou-se que, para $P$. stipulacea, os tratamentos não interferiram estatisticamente na massa seca da parte aérea e total (Tab. 1), enquanto para A. colubrina, não houve diferenças significativas apenas na massa seca da parte aérea (Tab. 2). Em todos os tratamentos, $P$. stipulacea alocou mais massa seca na parte aérea, enquanto $A$. colubrina no sistema radicular. Com ambas as espécies, o aumento da radiação fotossintetizante aumentou a partição de assimilados para o sistema radicular, conseqüentemente, aumentando a razão raiz/parte aérea a pleno sol. Em geral, plântulas crescidas em baixa irradiância alocam mais biomassa preferencialmente para o caule e folhas do que para as raízes (Kitajima 1994). Estas características são mais pronunciadas em espécies com crescimento mais rápido e são consideradas como uma resposta adaptativa ao sombreamento porque aumentam a razão fotossintética em relação à respiração, contribuindo para a manutenção de um balanço positivo e para a maximização do crescimento em condição de sombreamento (Lambers \& Poorter 1992).

As médias da razão raiz/parte aérea das plântulas de $A$. colubrina foram superiores às de $P$. stipulacea, em todos os tratamentos (Tab. 1 e Tab. 2), devido ao crescimento lento da parte aérea em detrimento do sistema radicular, como ocorre com as espécies intolerantes à sombra, sendo que o inverso ocorre para as espécies tolerantes (Whitmore 1990). Para ambas as espécies, houve uma tendência no aumento do peso radicular sob altas intensidades luminosas, podendo estar relacionado à maior restrição hídrica, que induz ao acúmulo de massa seca no sistema radicular, em detrimento do acúmulo de assimilados na parte aérea. Plântulas são mais suscetíveis aos períodos secos do que aquelas em estádios posteriores de desenvolvimento e que provavelmente já possuem sistema radicular substancial (Kitajima 1996). Assim, plântulas em ambientes estacionais devem apresentar rápido desenvolvimento inicial do sistema radicular para sobreviver aos meses de seca. A alta razão raiz/parte aérea é resultado de maior investimento de biomassa para as raízes, possibilitando maior absorção de água para suprir a demanda transpiratória em alta irradiância (Poorter 1999).

Em relação aos teores de clorofila observou-se, nas duas espécies estudadas, que a concentração de clorofila total tendeu a aumentar com o acréscimo do nível de sombreamento. Porém, não foram observadas diferenças significativas entre os tratamentos para plântulas de P. stipulacea. Para $A$. colubrina verificou-se diferenças significativas, sendo que os maiores teores de clorofila foram encontrados nas plântulas submetidas a $70 \%$ de sombra. Sabe-se que em condições adequadas de intensidade luminosa as moléculas de clorofilas estão constantemente sendo degradadas e sintetizadas, na mesma proporção, porém, sob radiações intensas, o processo degradativo ocorre de forma pronunciada, portanto folhas de sombra possuem maiores concentrações de clorofila total (Kramer \& Kozlowski, 1979). Para todos os tratamentos, A. colubrina apresentou maiores teores de clorofila quando comparados aos de P. stipulacea (Tab. 1 e Tab. 2). 
Tabela 1. Taxa de crescimento relativo da parte aérea (TCRPA), massa seca da raiz (MSR), parte aérea (MSPA), total (MST), relação raiz/parte aérea (MSR/MSPA), clorofila $a(\mathrm{Cl} a), b(\mathrm{Cl} b)$, clorofila total ( $\mathrm{Cl}$ total) e razão clorofila $a / b(\mathrm{Cl} a / b)$ das plântulas de Piptadenia stipulacea (Benth.) Ducke submetidas a diferentes tratamentos de sombra. Médias seguidas da mesma letra não diferem entre si pelo teste de Tukey a $5 \%$ de probabilidade.

\begin{tabular}{|c|c|c|c|c|c|c|c|c|c|}
\hline $\begin{array}{c}\text { Sombra } \\
(\%)\end{array}$ & $\begin{array}{c}\text { TCRPA } \\
\left(\mathrm{cm} \cdot \text { dias }^{-1}\right)\end{array}$ & $\begin{array}{l}\text { MSR } \\
(\mathrm{g})\end{array}$ & $\begin{array}{l}\text { MSPA } \\
(\mathrm{g})\end{array}$ & $\begin{array}{l}\text { MST } \\
(\mathrm{g})\end{array}$ & $\begin{array}{l}\text { MSR/ } \\
\text { MSPA }\end{array}$ & $\begin{array}{c}\text { Cl. } a \\
\left(\mu \mathrm{g} \cdot \mathrm{cm}^{-2}\right)\end{array}$ & Cl. $b\left(\mu \mathrm{g} \cdot \mathrm{cm}^{-2}\right)$ & $\begin{array}{l}\text { Cl. total } \\
\left(\mu \mathrm{g} \cdot \mathrm{cm}^{-2}\right)\end{array}$ & Cl. $a / b$ \\
\hline 0 & $0,032 \mathrm{a}$ & 7,18 a & $17,97 \mathrm{a}$ & $25,15 \mathrm{a}$ & $0,40 \mathrm{a}$ & $41,57 \mathrm{a}$ & $6,13 \mathrm{~b}$ & $47,70 \mathrm{a}$ & $8,27 \mathrm{a}$ \\
\hline 50 & $0,053 \mathrm{~b}$ & $6,04 \mathrm{ab}$ & $21,25 \mathrm{a}$ & $27,30 \mathrm{a}$ & $0,29 \mathrm{~b}$ & $52,03 \mathrm{a}$ & $11,67 \mathrm{ab}$ & $63,70 \mathrm{a}$ & $4,77 \mathrm{~b}$ \\
\hline 70 & $0,057 \mathrm{~b}$ & $5,48 \mathrm{~b}$ & $23,89 \mathrm{a}$ & $27,31 \mathrm{a}$ & $0,25 \mathrm{~b}$ & $55,17 \mathrm{a}$ & $13,05 \mathrm{a}$ & $68,25 \mathrm{a}$ & $4,42 \mathrm{~b}$ \\
\hline 90 & $0,060 \mathrm{~b}$ & $4,74 \mathrm{~b}$ & $17,26 \mathrm{a}$ & $22,00 \mathrm{a}$ & $0,28 \mathrm{~b}$ & $51,37 \mathrm{a}$ & $14,75 \mathrm{a}$ & $66,10 \mathrm{a}$ & $3,52 \mathrm{~b}$ \\
\hline
\end{tabular}

Tabela 2. Taxa de crescimento relativo da parte aérea (TCRPA), massa seca da raiz (MSR), parte aérea (MSPA), total (MST), relação raiz/parte aérea (MSR/MSPA), teores de clorofila $a(\mathrm{Cl} a)$, clorofila $b(\mathrm{Cl} b)$, clorofila total $(\mathrm{Cl}$ total) e razão clorofila $a / b(\mathrm{Cl} a / b)$ das plântulas de Anadenanthera colubrina (Vell.) Brenan var. cebil (Griseb.) Altshul submetidas a diferentes tratamentos de sombra. Médias seguidas da mesma letra não diferem entre si pelo teste de Tukey a 5\% de probabilidade.

\begin{tabular}{|c|c|c|c|c|c|c|c|c|c|}
\hline $\begin{array}{c}\text { Sombra } \\
(\%)\end{array}$ & $\begin{array}{c}\text { TCRPA } \\
\left(\mathrm{cm} \cdot \text { dias }^{-1}\right)\end{array}$ & $\begin{array}{l}\text { MSR } \\
(\mathrm{g})\end{array}$ & $\begin{array}{c}\text { MSPA } \\
(\mathrm{g})\end{array}$ & $\begin{array}{l}\text { MST } \\
(\mathrm{g})\end{array}$ & $\begin{array}{l}\text { MSR/ } \\
\text { MSPA }\end{array}$ & $\begin{array}{c}\text { Cl. } a \\
\left(\mu \mathrm{g} \cdot \mathrm{cm}^{-2}\right)\end{array}$ & Cl. $b\left(\mu \mathrm{g} \cdot \mathrm{cm}^{-2}\right)$ & $\begin{array}{l}\text { Cl. total } \\
\left(\mu \mathrm{g} \cdot \mathrm{cm}^{-2}\right)\end{array}$ & Cl. $a / b$ \\
\hline 0 & $0,016 \mathrm{a}$ & $12,75 \mathrm{a}$ & $4,37 \mathrm{a}$ & $17,12 \mathrm{a}$ & $2,88 \mathrm{a}$ & $44,60 \mathrm{~b}$ & $13,02 \mathrm{a}$ & $57,60 \mathrm{~b}$ & $4,55 \mathrm{a}$ \\
\hline 50 & $0,029 \mathrm{~b}$ & $10,49 \mathrm{a}$ & $4,95 \mathrm{a}$ & $15,44 \mathrm{ab}$ & $2,21 \mathrm{ab}$ & $64,85 \mathrm{ab}$ & $15,10 \mathrm{a}$ & $79,95 \mathrm{ab}$ & $4,30 \mathrm{a}$ \\
\hline 70 & $0,030 \mathrm{~b}$ & $10,76 \mathrm{a}$ & $5,79 \mathrm{a}$ & $16,56 \mathrm{a}$ & $1,98 \mathrm{bc}$ & $81,10 \mathrm{a}$ & $19,02 \mathrm{a}$ & $92,62 \mathrm{a}$ & $4,80 \mathrm{a}$ \\
\hline 90 & $0,029 \mathrm{~b}$ & $6,15 b$ & $4,77 \mathrm{a}$ & $10,91 \mathrm{~b}$ & $1,31 \mathrm{c}$ & $71,55 \mathrm{ab}$ & $17,32 \mathrm{a}$ & $88,87 \mathrm{ab}$ & $4,15 \mathrm{a}$ \\
\hline
\end{tabular}

Foi observado que, para plântulas de A. colubrina, a razão clorofila $a / b$ não diferiu entre os tratamentos de sombra. Para plântulas de P. stipulacea observou-se que a razão clorofila $a / b$ diminuiu com o acréscimo de sombra, apresentando menor média a $90 \%$ de sombreamento. Segundo Kozlowski et al. (1991), em geral, a proporção entre clorofila $a$ e $b$ decresce com o aumento do sombreamento, devido a maior concentração de clorofila $b$. Essa concentração se deve a degradação mais lenta da clorofila $b$ em relação à clorofila $a$ (Engel \& Poggiani 1991) e a maior proporção do fotossistema II que é mais rico em clorofila $b$ (Nakazono et al. 2001). Dessa forma, a capacidade das plantas em maximizar a captura por luz em ambientes sombreados está principalmente relacionada com a relação clorofila $a / b$ (Engel \& Poggiani 1991).

Em síntese, pode-se concluir que as espécies estudadas apresentam diferentes exigências de luz durante o crescimento inicial, pois, ao compará-las, nota-se que P. stipulacea apresentou maior taxa de crescimento relativo, maior diâmetro a pleno sol, menor razão raiz/parte aérea e menor conteúdo de clorofila total em detrimento de A. colubrina. Os melhores resultados de P. stipulacea a pleno sol e A. colubrina em níveis intermediários de sombra corroboraram a hipótese deste trabalho e poderiam, a priori, explicar porque estas espécies são mais encontradas, respectivamente, em ambientes perturbados e conservados.

\section{Agradecimentos}

Os autores agradecem à Coordenação de Aperfeiçoamento de Pessoal de Nível Superior (CAPES) pelo apoio financeiro e às equipes do Núcleo de Ensino e Pesquisa em
Agricultura Urbana (NEPAU) e do Laboratório de Análises de Sementes (LAS) pela disponibilidade do espaço e apoio nas coletas e análises.

\section{Referências}

Albuquerque, U.P. \& Andrade, L.H.C. 2002. Conhecimento botânico tradicional e conservação em uma área de caatinga no Estado de Pernambuco, Nordeste do Brasil. Acta Botanica Brasilica 16(3): 273-285.

Andrade, L.A.; Pereira, I.M.; Leite, U.T. \& Barbosa, M.R.V. 2005. Análise da cobertura de duas fitofisionomias de caatinga, com diferentes históricos de usos, no município de São João do Cariri, estado da Paraíba. Cerne 11(3): 253-262

Barbosa, D.C.A. 2003. Estratégias de germinação e crescimento de espécies lenhosas da caatinga com germinação rápida. Pp.625-656. In: Leal, I.R.; Tabarelli, M.; Silva, J.M.C. (Ed.). Ecologia e conservação da caatinga. Recife: Universidade Federal de Pernambuco.

Barbosa, M.R.V.; Lima, I.B.; Lima, J.R.; Cunha, J.P.; Agra, M.F. \& Thomas, W.W. 2007. Vegetação e flora no Cariri paraibano. Oecologia Brasiliensis 11(3): 313-322.

Böhm, W. 1979. Methods of studying root system. Berlin, Springer-Verlag

Braga, R. 1976. Plantas do Nordeste, especialmente do Ceará. 3 ed. Fortaleza: ESAM

Campos, M.A.A. \& Uchida, T. 2002. Influência do sombreamento no crescimento de mudas de três espécies amazônicas. Pesquisa Agropecuária Brasileira 37(3): 281-288.

Duz, S.R.; Siminski, A.; Santos, M. \& Paulilo, M.T.S. 2004. Crescimento inicial de três espécies arbóreas da Floresta Atlântica em resposta a variação de luz. Revista Brasileira de Botânica 27(3): 587-596.

Engel, V.L. \& Poggiani, F. 1991. Estudo da concentração de clorofila nas folhas e seu espectro de absorção de luz em função do sombreamento em mudas de quatro espécies florestais nativas. Revista Brasileira de Fisiologia Vegetal 3(1): 39-45.

Felfili, J.M.; Hilgbert, L.F.; Franco, A.C.; Sousa-Silva, J.C.; Resende, A.V. \& Nogueira, M.V.P. 1999. Comportamento de plântulas de Sclerolobium paniculatum Vog. Var. rubiginosum (TUL.) Benth. sob diferentes níveis de sombreamento em viveiro. Revista Brasileira de Botânica 22(2): 297-301. 
Ferreira, D.F. 2008. SISVAR: um programa para análises e ensino de estatística. Revista Symposium 6(2): 36-41.

Kitajima, K. 1996. Ecophysiology of tropical tree seedlings. Pp. 559-596. In: Mulkey, S.S.; Chazdon, R.L. \& Smith, A.P. (Eds.). Tropical Forest Plant Ecophysiology. New York, Chapman and Hall.

Kitajima, K. 1994. Relative importance of photosynthetic traits and allocation patterns as correlates of seedling shade tolerance of 13 tropical trees. Oecologia 98: 419-428.

Kozlowski, T.; Kramer, P.J. \& Pallardy, S.G. 1991. The physiological ecology of woody plants. London, Academic Press.

Kramer, T. \& Kozlowski, T. 1979. Physiology of woody plants. New York, Academic.

Lambers, H. \& Poorter, H. 1992. Inherent variation in growth rate between higher plants: a search for physiological causes and ecological consequences. Advances in Ecological Research 23: 187-261.

Larcher, W. 2006. Ecofisiologia vegetal. São Carlos, Editora RiMa.

Lüttge, U. 1997. Physiological ecology of tropical plants. Germany, Springer-Verlag Berlin Heidelberg.

Maia, N.G. 2004. Caatinga: árvores e arbustos e suas utilidades. São Paulo, Editora Livro e Arte.

Nakazono, E.M.; Costa, M.C.; Futatsugi, K. \& Paulilo, M.T.S. 2001. Crescimento inicial de Euterpe edulis Mart. em diferentes regimes de luz. Revista Brasileira de Botânica 24(2): 173-179.

Osunkoya, O.O.; Ash, J.E.; Hopkins, M.S. \& Graham, A.W. 1994. Influence of seed size and seedling ecological attributes on shade-tolerance in northern Queensland. Journal of Ecology 82: 149-163.

Pereira, I.M.; Andrade, L.A.; Costa, J.R.M. \& Dias, J.M. 2001. Regeneração natural em um remanescente de caatinga sob diferentes níveis de perturbação, no agreste paraibano. Acta Botânica Brasílica 53(3): 413-426.

Poorter, L. 1999. Growth responses of 15 rain-forest tree species to a light gradient: the relative importance of morphological and physiological traits. Functional Ecology 13: 396-410.

Queiroz, J.A.; Trovão, D.M.B.M.; Oliveira, A.B. \& Oliveira, E.C.S. 2006. Análise da Estrutura Fitossociológica da Serra do Monte, Boqueirão, Paraíba. Revista de Biologia e Ciências da Terra 6(1): 251- 259.
Reis, M.G.F.; Reis, G.G.; Regazzi, A.J. \& Leles, P.S.S. 1991. Crescimento e forma do fuste de mudas de jacarandá-da-bahia (Dalbergia nigra Fr. Allem.), sob diferentes níveis de sombreamento e tempo de cobertura. Revista Árvore 15(1): 23-24.

Silva, R.R.; Freitas, G.A.; Siebeneichler, S.C.; Mata, J.F. \& Chagas J.R. 2007. Desenvolvimento inicial de plântulas de Theobroma grandiflorum (Willd. ex Spreng.) Schum. sob influência de sombreamento. Acta Amazônica 37(3): 365-370.

Smith, H. \& Whitelam, G.C. 1990. Phytochrome, a family of photoreceptors with multiple physiological roles. Plant Cell and Environment 13: 695-707.

Souza, G.M.; Balmant, B.D.; Vítolo, H.F.; Gomes, K.B.P.; Florentino, T.M.; Catuchi, T.A. \& Vieira, W.L. 2009. Estratégias de utilização de luz e estabilidade do desenvolvimento de plântulas de Cordia superba Cham. (Boraginaceae) crescidas em diferentes ambientes luminosos. Acta Botanica Brasilica 23(2): 474-485.

Statsoft. 2004. Statistica: data analysis software system: version 7.0. Tulsa: Statsoft.

Swaine, M. D. \& Whitmore, T. C. 1988. On the definition of ecological species groups in tropical rain forests. Vegetation 75: 81-86.

Taiz, L. \& Zeiger, E. 2004. Fisiologia vegetal. 3. ed. Porto Alegre, Artmed.

Thompson, W.A.; Huang, L.K. \& Kriedemann, P.E. 1992. Photosynthetic response to light and nutrients in sun-tolerant and shade tolerant rainforest trees. II. Leaf gas exchange and component processes of photosynthesis. Australian Journal of Plant Physiology 19: 19-42.

Uchida, T. \& Campos, M.A.A. 2000. Influência do sombreamento no crescimento de mudas de cumaru (Dipteryx odorata (AUBL.) WILLD. - Fabaceae), cultivdas em viveiro. Acta Amazônica 30(1): 107-114.

Valladares, F.; Wright, S.J.; Lasso, E.; Kitajima, K. \& Pearcy, R.W. 2000. Plastic phenotypic response to light of 16 congenetic shrubs from a Panamanian rainforest. Ecology 81(1): 1925-1936.

Whitham, F.H.; Blaydes, D.F.; Devlin, R.M. 1971. Experiments in Plant Physiology. New York, D. Van Nostrand Company.

Whitmore, T. C. 1990. Tropical Rain Forest dynamics and its implications for management. Pp.67-89. In: Gomespompa, A.; Whitmore,T. C. \& Hadley, M. Rain forest regeneration and management. Paris, UNESCO and The Part Eenon Publishing Group. 